\title{
Prophylactic pelvic irradiation as part of primary therapy in uterine sarcomas
}

\author{
BENGT SORBE and BIRGIT JOHANSSON
}

\author{
Department of Gynecological Oncology, University Hospital, S-701 85 Örebro, Sweden
}

Received November 30, 2007; Accepted January 15, 2008

\begin{abstract}
In a complete geographic series of 155 cases of primary uterine sarcomas, prophylactic pelvic irradiation was used as standard postoperative therapy in the majority of the cases. Vaginal brachytherapy was also added as a boost. The histology was leiomyosarcoma in 62 cases (40\%), carcinosarcoma in $60(39 \%)$, endometrial stromal sarcoma in 25 $(16 \%)$, and other types in 8 cases $(5 \%)$. The primary surgery was extended hysterectomy in 11 cases (7\%), simple hysterectomy in $110(71 \%)$, and supravaginal hysterectomy in 12 (8\%). In 22 cases (14\%) no major surgery was possible. In the complete series, 62 recurrences $(40 \%)$ were recorded. Local (9\%), regional (9\%), and distant recurrences $(28 \%)$ were the most frequent. The type of surgery was associated with the risk of tumor recurrence. Extended surgery reduced the risk of local and regional recurrences. The 5-year overall survival rate was $42 \%$ and the recurrence-free survival (RFS) was $37 \%$. The number of mitoses was significantly $(\mathrm{P}=0.007)$ associated with survival. The locoregional RFS rate was $75 \%$ for patients treated with adjuvant irradiation and $83 \%$ for patients treated with primary surgery alone. Serious late tissue reactions from the bladder and intestine occurred in $7 \%$ of the irradiated cases. The locoregional tumor control rate was high in this series of patients, but no significant difference was found between patients treated with surgery alone and surgery plus postoperative pelvic irradiation. This was true for all histological subtypes of the uterine sarcomas. However, this was not a randomized study and selection bias cannot be ruled out.
\end{abstract}

\section{Introduction}

Uterine sarcomas are rare tumors and represent about $1 \%$ of all gynecological malignancies and $2-5 \%$ of all uterine malignancies $(1,2)$. The incidence of sarcomas of the uterus

Correspondence to: Professor Bengt Sorbe, Department of Gynecological Oncology, University Hospital, S-701 85 Örebro, Sweden

E-mail: bengt.sorbe@orebroll.se

Key words: uterine sarcomas, prophylactic irradiation, surgery, prognosis reported in the literature is 1.7 per 100,000 women (2). The mean age of patients varies with the histology type. Patients with carcinosarcomas are significantly older than patients with other histological types of sarcomas. Mixed mullerian mesodermal tumors (MMMT; carcinosarcomas) are most frequent, followed by leiomyosarcomas (LMS) and endometrial stromal sarcomas (ESS). Other rare types (rhabdomyosarcomas, liposarcomas, chondrosarcomas, undifferentiated sarcomas) account for less than $5 \%$ of uterine sarcomas (3). The overall prognosis for all stages of primary uterine sarcomas is unfavorable and the 5-year survival rate is reported to be as low as $30-40 \%$ (4). Approximately $50 \%$ of patients with uterine sarcomas present with FIGO stage I disease at diagnosis. Advanced stages (FIGO III-IV) are recorded in $40 \%$ of the tumors (5). Uterine sarcomas spread hematogenously (6), and the prognosis in advanced stages is extremely poor. However, the rate of recurrence is also high (40-60\%) in early stage disease (FIGO stage I-II) (7-10). In $35 \%$ of cases the recurrences are localized in the pelvis and in $65 \%$ as distant metastases (8).

Surgery is the cornerstone in the treatment of uterine sarcomas (11). Extended, radical surgery is not routine (12), and the value of pelvic and paraaortic lymphadenectomy has been questioned $(7,9)$. Residual tumor seems to be an important prognostic factor $(7,13,14)$. The benefits of postoperative radiotherapy and chemotherapy are still under debate $(5,7,11,15-17)$. Tumor stage, patient age, parity, histology type and mitotic count are known prognostic factors $(8,9,18)$. Depth of myometrial invasion, tumor grade, and lymphovascular space invasion and residual disease are probably also significant prognostic factors $(7,19)$.

In the present retrospective study postoperative adjuvant pelvic radiotherapy was standard and an integrated part of the primary treatment of all uterine sarcomas for a long period of time. Chemotherapy was not used in the adjuvant setting. The clinical outcome is presented for a large series of sarcomas with this treatment concept. Recurrences, progression-free survival and overall survival are presented as well as side effects related to the combined treatment with surgery and pelvic irradiation.

\section{Patients and methods}

A complete geographic series of uterine sarcomas in FIGO stages I-IV, treated during the years 1975-2003 in the Örebro medical region, in central Sweden, was used in a retrospective study, evaluating the extent of surgery and postoperative 
Table I. Tumor characteristics of the complete series $(n=155)$.

\begin{tabular}{lrr}
\hline Tumor characteristics & Number & Percent \\
\hline Stage & & \\
I & 95 & 61.3 \\
II & 1 & 6.4 \\
III & 26 & 16.8 \\
IV & 24 & 15.5 \\
Histology & & \\
Leiomyosarcomas & 62 & 40.0 \\
Endometrial stromal sarcomas & 25 & 16.1 \\
Carcinosarcomas & 60 & 38.7 \\
Other types & \\
Mitoses per 10 HPF & 8 & 5.2 \\
1-5 & & \\
6-10 & 9 & 5.8 \\
11-20 & 21 & 13.5 \\
21-30 & 14 & 9.0 \\
$>30$ & 19 & 12.2 \\
Unknown & 7 & 4.5 \\
\hline
\end{tabular}

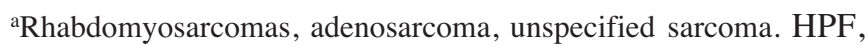
high-power fields.

Table II. Surgical techniques used in the complete series.

\begin{tabular}{lrr}
\hline Surgical technique & Number & Percent \\
\hline Type of surgery & & \\
Radical hysterectomy & 11 & 7.1 \\
Total hysterectomy & 110 & 71.0 \\
Supravaginal hysterectomy & 12 & 7.7 \\
Multiple excisions & 3 & 1.9 \\
No surgery & 19 & 12.3 \\
Surgical outcome & & \\
Radical surgery & 102 & 65.8 \\
Uncertain radicality & 2 & 1.3 \\
Non-radical surgery & 32 & 20.6 \\
No surgery & 19 & 12.3 \\
Lymph node dissection & & \\
Yes & 11 & 9.1 \\
No & 144 & \\
\hline
\end{tabular}

adjuvant radiotherapy. In all, 155 patients were included in the study (Table I). The mean age of the patients was 64.5 years (range 31-94 years). All histological slides were reviewed at the Department of Pathology, Örebro University Hospital. Ninety-five tumors were in FIGO stage I (61\%), 10 in stage II $(6 \%), 26$ in stage III $(17 \%)$, and 24 in stage IV $(15 \%)$. The primary surgery was total abdominal hysterectomy in 110 cases $(71 \%)$, supravaginal hysterectomy in 12 cases
Table III. Radiotherapy types, targets and schedules used in the complete series.

\begin{tabular}{lrr}
\hline Radiotherapy & Number & Percent \\
\hline Type & & \\
Postoperative & 97 & 62.6 \\
Preoperative & 11 & 7.1 \\
None & 47 & 30.3 \\
Target & & \\
Whole abdomen & 3 & 1.9 \\
Lower abdomen & 9 & 5.8 \\
Pelvis (A-P fields) & 58 & 37.4 \\
Pelvis (4 fields) & 38 & 25.2 \\
Schedule & & \\
1x1.4 Gy x14 & & \\
$1 \times 1.8$ Gy x22 & 3 & 8.8 \\
1x2.0 Gy x20 & 9 & 44.4 \\
1x2.0 Gy x23 & 48 & 11.1 \\
$1 \times 2.0$ Gy x25 & 30 & 5.6 \\
Other schedules & 12 & \\
\hline
\end{tabular}

${ }^{\text {aW }}$ hole abdominal A-P fields, ${ }^{b}$ lower abdominal A-P fields, ${ }^{c}$ pelvic fields.

(8\%) and Wertheim-Meigs surgery in 11 cases (7\%). In 22 cases $(14 \%)$ only multiple biopsies were taken due to advanced disease (Table II). The surgery was performed at three departments of gynecology and obstetrics, but all patients were then referred to the Department of Gynecological Oncology, Örebro University Hospital, for postoperative evaluation and treatment. The time interval between surgery and external beam radiotherapy was 4-6 weeks. The main type of radiotherapy was adjuvant pelvic irradiation. Two- or four-field techniques were used. Photon beams were used for treatment daily, 5 days a week. The doses and fractionation of radiotherapy are presented in Table III. All patients treated with external beam therapy also received intracavitary vaginal brachytherapy as a boost to the upper two-thirds of the vaginal walls. The dose per fraction varied from 2.5 to $7.0 \mathrm{~Gy}$ (specified at $5 \mathrm{~mm}$ below the surface of the vaginal wall). The number of fractions varied from 2 to 6 . Most treatments were given on an outpatient basis.

All patients were followed-up for at least 10 years and no cases were lost in follow-up. The mean follow-up time was 160 months (range 21-367 months). During all visits symptoms and signs related to the therapy were recorded.

The first follow-up visit was after 1 month, then every 3 months during the first year, every 4 months during the second and third years, every 6 months up to five years and then annually up to 10 years. All data were collected in a computerized database at the Department of Gynecological Oncology, Örebro.

In the statistical analyses, survival curves were generated using the Kaplan-Meier technique and differences were tested with the Chi-square or log-rank tests. The Chi-square 
Table IV. Sites of recurrences.

\begin{tabular}{lcr}
\hline Site & Number & Percent \\
\hline Vagina & 4 & 2.6 \\
Pelvis & 6 & 3.9 \\
Abdomen & 12 & 7.7 \\
Liver & 5 & 3.2 \\
Lung & 37 & 23.9 \\
Bone & 7 & 4.5 \\
CNS & 1 & 0.7 \\
Site & Number & Percent \\
\hline Local & 8 & 12.9 \\
Regional & 10 & 16.1 \\
Distant metastases & 35 & 56.5 \\
Local + regional & 1 & 1.6 \\
Local + distant & 5 & 8.1 \\
Regional + distant & 3 & 4.8 \\
\hline
\end{tabular}

${ }^{\text {aPercent }}$ of all patients $(n=155) .{ }^{b}$ Percent of all recurrences $(n=62)$.

Table V. Type of surgery and tumor recurrences.

\begin{tabular}{lcc}
\hline Type of surgery & Number & Percent \\
\hline Complete series $(\mathrm{n}=155)^{\mathrm{a}}$ & & \\
Radical hysterectomy & $2 / 11$ & 18.2 \\
Simple hysterectomy & $53 / 110$ & 48.2 \\
Supravaginal hysterectomy & $2 / 12$ & 16.7 \\
No surgery & $4 / 22$ & 18.2 \\
Stage I-II (n=91) & & \\
Radical hysterectomy & $2 / 8$ & 25.0 \\
Simple hysterectomy & $40 / 78$ & 51.3 \\
Supravaginal hysterectomy & $2 / 5$ & 40.0 \\
\hline
\end{tabular}

${ }^{\text {aPearson Chi-square }=12.378, \mathrm{P}=0.006 .}$ ' $P$ earson Chi-square $=2.155$, $\mathrm{P}=0.340$.

test was also used for comparison of the proportions and the independent t-test and ANOVA statistics were used to compare the means. Logistic regression analysis was used in multivariate analyses of the risk of tumor recurrences and late tissue reactions. P-values $<0.05$ were regarded as statistically significant. The Statistica (StatSoft Inc., Tulsa, AZ, USA) software package (version 7.1, 2005) was used for the statistical analyses.

\section{Results}

In the complete series of 155 uterine sarcomas 62 recurrences $(40.0 \%)$ were recorded. Local and regional (pelvic lymph nodes) recurrences were each recorded in $9 \%$ of cases, and distant metastases in $28 \%$ (Table IV). The median time from
Table VI. Tumor recurrences (all sites) versus radiotherapy in stages I-II.

\begin{tabular}{lcc}
\hline Radiotherapy & Number & Percent \\
\hline Complete series $(\mathrm{n}=105)^{\mathrm{a}}$ & & \\
$\quad$ Radiotherapy & $41 / 83$ & 49.4 \\
$\quad$ No radiotherapy & $8 / 22$ & 36.4 \\
Leiomyosarcomas $(\mathrm{n}=40)^{\mathrm{b}}$ & & \\
$\quad$ Radiotherapy & $16 / 30$ & 53.3 \\
$\quad$ No radiotherapy & $4 / 10$ & 40.0 \\
Carcinosarcomas $(\mathrm{n}=40)^{\mathrm{c}}$ & & \\
$\quad$ Radiotherapy & $20 / 36$ & 55.6 \\
$\quad$ No radiotherapy & $2 / 4$ & 50.0 \\
Endometrial stromal sarcomas $(\mathrm{n}=21)^{\mathrm{d}}$ & & \\
$\quad$ Radiotherapy & $3 / 14$ & 21.4 \\
$\quad$ No radiotherapy & $2 / 7$ & 28.6 \\
\hline
\end{tabular}

${ }^{\mathrm{a}}$ Pearson Chi-square $=1.187, \mathrm{P}=0.276 .{ }^{\mathrm{b}} \mathrm{Pearson}$ Chi-square $=0.533$, $\mathrm{P}=0.465$. ${ }^{\mathrm{c}} \mathrm{Pearson}$ Chi-square $=0.045, \mathrm{P}=0.832$. ${ }^{\mathrm{d}} \mathrm{Pearson}$ Chisquare $=0.131, \mathrm{P}=0.717$.

treatment to recurrence was 12 months. Type of surgery was associated with the risk of tumor recurrence. More extensive surgery (Wertheim-Meigs) was associated with fewer recurrences than conventional hysterectomy with bilateral salpingo-oophorectomy. Supravaginal hysterectomy did not seem to further deteriorate local tumor control in stage I sarcomas (Table V). The surgery was radical (tumor-free margins) in 102 cases (75\%), non-radical in 32 cases $(24 \%)$ and with uncertain surgical margins in 2 cases $(1.5 \%)$. Pelvic lymph node dissection was performed in only 11 patients $(8 \%)$ as part of Wertheim-Meigs surgery, but this extensive procedure was not standard treatment in this series of uterine sarcomas. In 19 cases no surgery was performed.

Radiotherapy was administered in 109 cases (70\%) in total. In 97 cases (63\%) it was administered as postoperative adjuvant therapy, and in 12 cases $(8 \%)$ as preoperative radiotherapy with curative intent. In 46 cases (30\%) no radiotherapy was given. Whole abdominal irradiation was used in 3 cases, lower abdominal irradiation in 9 cases and pelvic irradiation (A-P fields or 4-field technique) in 96 cases $(88 \%)$. In 101 cases $(65 \%)$ brachytherapy was added to the external beam therapy. In 87 cases $(56 \%)$ vaginal irradiation was added as part of the postoperative radiotherapy, and in 14 cases $(9 \%)$ intrauterine irradiation was given as preoperative therapy or as a definitive local therapy in cases with a remaining uterus.

All types and sites of tumor recurrences (Table VI) as well as local and regional tumor control and the risk of recurrences were similar for cases treated with adjuvant radiotherapy and for cases treated with surgery alone in stages I-II (Table VII). The odds ratio for locoregional recurrences in stage I (all histological types) was 0.91 (95\% CI: 0.26-3.19) for adjuvant radiotherapy versus surgery alone. Distant metastases were slightly more frequent, but 
Table VII. Locoregional recurrences versus radiotherapy in stages I-II.

\begin{tabular}{lrr}
\hline Radiotherapy & Number & Percen \\
\hline Complete series $(\mathrm{n}=105)^{\mathrm{a}}$ & & \\
$\quad$ Radiotherapy & $14 / 83$ & 16.9 \\
$\quad$ No radiotherapy & $4 / 22$ & 18.2 \\
Leiomyosarcomas $(\mathrm{n}=40)^{\mathrm{b}}$ & & \\
$\quad$ Radiotherapy & $5 / 30$ & 16.7 \\
$\quad$ No radiotherapy & $2 / 10$ & 20.0 \\
Carcinosarcomas $(\mathrm{n}=40)^{\mathrm{c}}$ & & \\
$\quad$ Radiotherapy & $8 / 36$ & 22.2 \\
$\quad$ No radiotherapy & $1 / 4$ & 25.0 \\
Endometrial stromal sarcomas $(\mathrm{n}=21)^{\mathrm{d}}$ & & \\
$\quad$ Radiotherapy & $0 / 14$ & 0.0 \\
$\quad$ No radiotherapy & $1 / 7$ & 14.3 \\
\hline
\end{tabular}

aPearson Chi-square $=0.021, \mathrm{P}=0.884 .{ }^{\mathrm{b}} \mathrm{Pearson}$ Chi-square $=0.058$, $\mathrm{P}=0.810$. ${ }^{\mathrm{c}} \mathrm{Pearson}$ Chi-square $=0.159, \mathrm{P}=0.900$. ${ }^{\mathrm{d}} \mathrm{Pearson}$ Chisquare $=2.100, \mathrm{P}=0.147$.

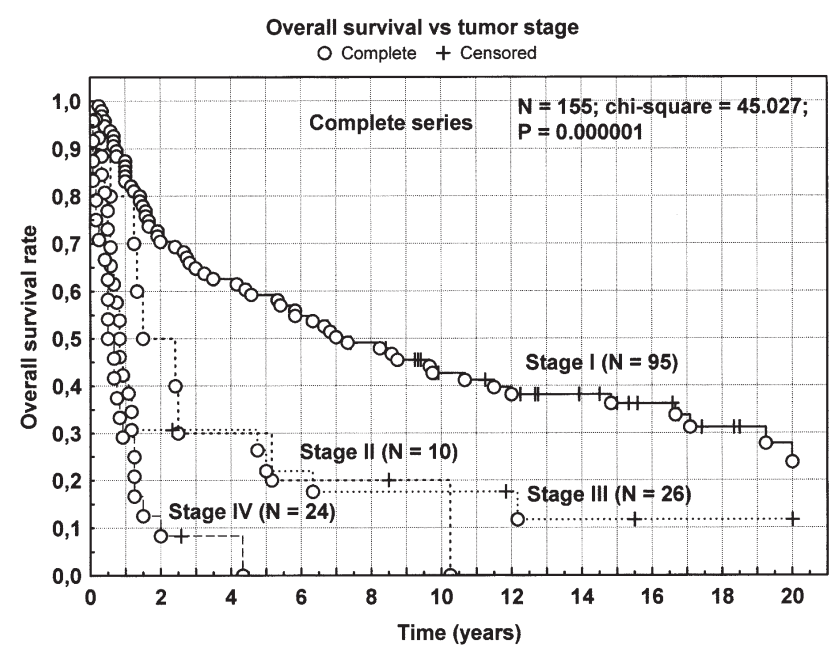

Figure 1. The overall survival rate versus tumor stage in the complete series $(n=155)$.

not statistically significant, in the radiotherapy group and this was true for all histological types. The odds ratio for distant metastases in stage I (all histological types) was 2.06 (95\% CI: 0.67-6.33) for adjuvant radiotherapy versus surgery alone. This may reflect a selection bias with regard to radiotherapy. Age was not associated with the risk of any type of tumor recurrence $(\mathrm{OR}=1.00 ; \mathrm{P}=0.951)$.

The 5-year overall survival rate for the complete series was $42 \%$. In stage I the survival rate was $59 \%$ and in stage II $30 \%$ (Fig. 1). In the complete series 95 patients (61\%) died due to their sarcomas and 19 patients $(12 \%)$ due to other, non-sarcoma related, diseases. The 5-year recurrence-free survival (RFS) rate was $37 \%$. In stages I-II the RFS was

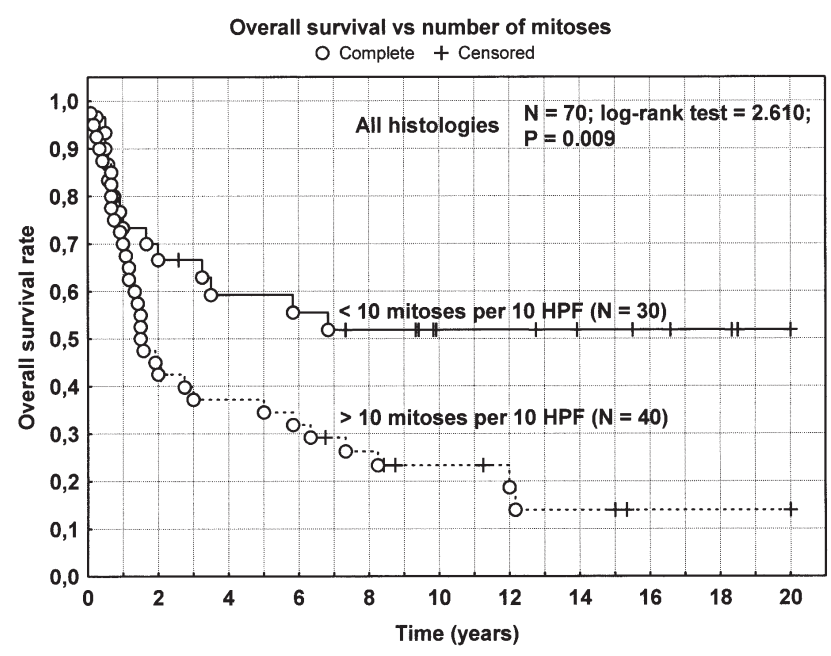

Figure 2. The recurrence-free survival rate versus number of mitoses in evaluable cases $(n=70)$.

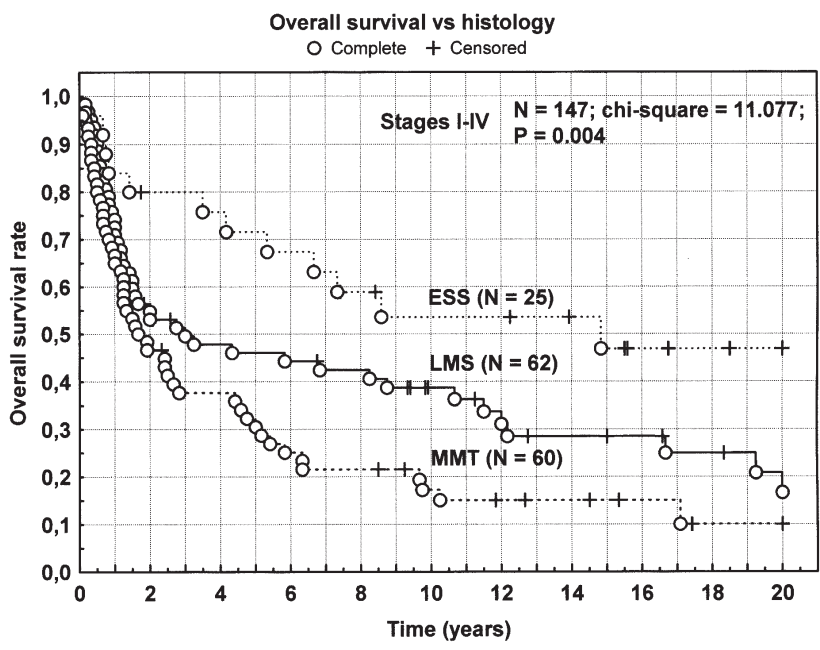

Figure 3 . The overall survival rate versus type of histology in the complete series $(n=147)$.

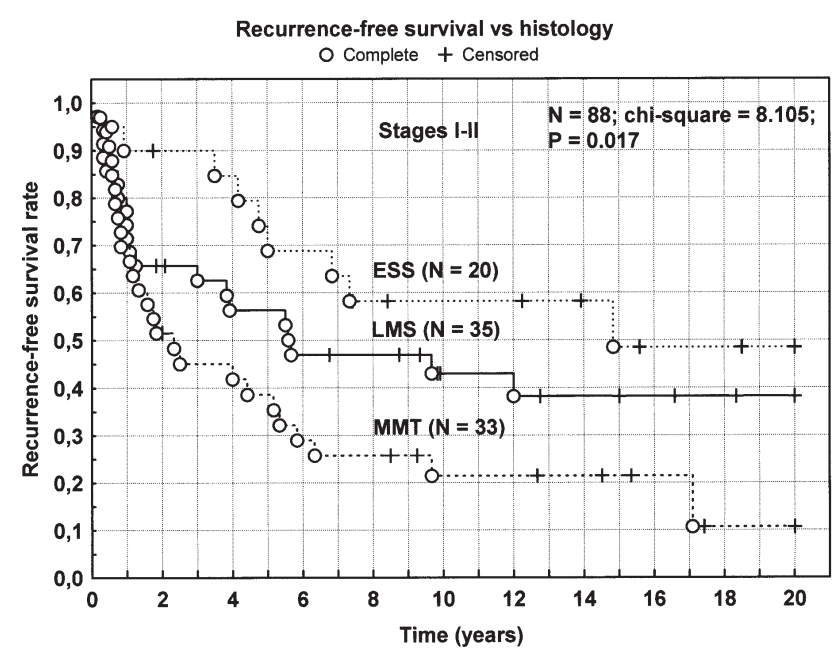

Figure 4. The recurrence-free survival rate versus histology type in the series of stage I-II tumors $(\mathrm{n}=88)$. 
Table VIII. Radiation reactions $(\mathrm{n}=109)$.

\begin{tabular}{lrr}
\hline Radiation reactions & Number & Percent \\
\hline Early & & \\
$\quad$ Intestinal grade 1 (diarrhea) & 84 & 77.1 \\
Intestinal grade 2 (diarrhea with blood) & 1 & 0.9 \\
Late & & \\
Intestinal grade 1 (diarrhea) & 14 & 12.8 \\
Intestinal grade 2 (diarrhea with blood) & 10 & 9.2 \\
Intestinal grade 3 (strictures) & 5 & 4.6 \\
Intestinal grade 4 (fistulas) & 2 & 1.8 \\
Bladder grade 2 (hematuria) & 2 & 21.8 \\
Bladder grade 3 (fistula) & 1 & 0.9 \\
\hline
\end{tabular}

$51 \%$, and in stages III-IV the progression-free survival was only $8 \%$. The 5 -year pelvic disease control was $81 \%$ in stage I, $80 \%$ in stage II, and $58 \%$ for more advanced stages. The number of mitoses was associated with the recurrence-free and overall survival rate (Fig. 2). The most efficacious cutoff level for the number of mitoses was 10 per 10 high-power fields (HPF). Carcinosarcomas showed a higher mitosis density $(80 \%>10$ mitoses/HPF) than leiomyosarcomas $(53 \%$ $>10$ mitoses/HPF) and stromal cell sarcomas $(45 \%>10$ mitoses/HPF). The mean number of mitoses per $10 \mathrm{HPF}$ was significantly different for the various types of sarcomas (ANOVA analysis; $\mathrm{P}=0.043$ ). The mean number of mitoses per 10 HPF was 16.5 for leiomyosarcomas, 20.3 for endometrial stromal sarcomas and 30.1 for carcinosarcomas. In stages I-II, type of surgery (radical hysterectomy, conventional total abdominal hysterectomy or supravaginal hysterectomy) was associated with recurrence rate. The overall recurrence rate was $25 \%$ after Wertheim-Meigs surgery but $50 \%$ after ordinary total hysterectomy and bilateral salpingo-oophorectomy or supravaginal hysterectomy. This difference was not statistically significant (Pearson Chi-square; $\mathrm{P}=0.175$ ), however probably due to the small number of patients $(n=8$ in FIGO stages I-II) in the extended surgery group.

In the complete series the locoregional recurrence-free survival rate was $75 \%$ for patients treated with adjuvant irradiation and $83 \%$ for patients treated with surgery alone. For patients with stage I tumors the corresponding figures were 81 and $82 \%$, respectively.

There was a statistically significant difference $(\mathrm{P}=0.004)$ in overall survival with regard to the histological type of the sarcoma (Fig. 3). Endometrial stromal cell sarcoma cases had the best survival (71\% 5-year survival) and carcinosarcoma cases (mixed mullerian tumors) the worst (30\% 5-year survival) with leiomyosarcoma cases in between with a $47 \%$ overall survival rate. Recurrence-free survival was also highly significantly $(\mathrm{P}=0.017)$ different for the three main types of uterine sarcomas in the complete series and also for stage I-II tumors (Fig. 4). The stage distribution was different $(\mathrm{P}=0.007)$ for endometrial stromal sarcomas $(84 \%$ stage $\mathrm{I})$ and for leiomyosarcomas (65\% stage I) and carcinosarcomas (53\% stage I).
Postoperative complications were not recorded in this series. Acute tissue reactions during irradiation were common, e.g. diarrhea, and were recorded in $55 \%$ of the cases. Late tissue reactions after irradiation (any type and grade) were recorded in 30 cases $(19 \%)$. In 8 cases $(7 \%)$ serious late reactions from the intestine or bladder, e.g. strictures or fistulas, were recorded (Table VIII).

\section{Discussion}

Uterine sarcomas belong to a heterogeneous group of female malignancies with unfavorable prognosis despite the fact that $50 \%$ of cases are diagnosed in stage I, and a consensus on standardized treatment is still lacking. Surgery is a cornerstone in primary therapy but the extent of surgery and the value of lymph node dissection have been under debate $(7,20,21)$. The value of adjuvant postoperative therapy is even more controversial and this is true for both radiotherapy and chemotherapy $(17,22)$. A number of nonrandomized, retrospective studies have suggested the benefit of radiotherapy, especially with regard to local and regional tumor control $(5,23-29)$. In a number of other studies no convincing improvement in tumor control or survival rate was shown $(30,31)$. Over the years, interest has been focused on the role of chemotherapy both as an adjuvant treatment and in combination regimens (16,32-35). The problem is the same as for radiotherapy with diverging results and conclusions from existing studies, including both randomized and non-randomized trials $(7,36)$. Postoperative sequential treatment with chemotherapy and radiotherapy has also been proposed (37). Palliative chemotherapy for patients with advanced, unresectable disease who are symptomatic is a reasonable treatment (38). Uterine sarcomas spread hematogenously, but the rate of locoregional recurrences is also high (40-60\%), even in early stages. The concept of pelvic and vaginal irradiation is therefore of interest and should be further evaluated. Since more than $60 \%$ of recurrences are distant metastases adjuvant chemotherapy is also worthwhile as a single treatment or in combination with radiotherapy.

In the present retrospective study a large series of uterine sarcomas were treated with primary surgery and postoperative adjuvant pelvic radiotherapy as the main line. A smaller number of the patients did not receive any radiotherapy. Since this study was not randomized this smaller group of patients may not be comparable with respect to a number of background factors when compared with the main group receiving radiotherapy. Due to primary advanced disease a smaller number of patients did not undergo primary surgery, but only palliative measures.

Tumor stage, histology type and number of mitoses were confirmed to be important prognostic factors in this series. Age was not a significant prognostic factor, however. Extended surgery according to Wertheim-Meigs seems to be of benefit compared with conventional total abdominal hysterectomy or supravaginal hysterectomy performed in certain cases with an unknown primary diagnosis. Adjuvant postoperative pelvic irradiation with or without vaginal irradiation was part of standard therapy in this series of patients. In a retrospective series like this it is difficult to 
evaluate the additive value of this type of radiotherapy. The results for the complete series can be presented as the outcome for patients treated according to this concept of primary surgery and postoperative adjuvant radiotherapy. The outcome data, e.g. recurrence rate, recurrence-free and overall survival rate compare well with data presented from other studies in the literature. The 5-year pelvic disease control was $80 \%$ in stage I-II compared to $67 \%$ in a series from France reported on by Benoit et al (11). However, the prognosis is still poor for this group of patients and this is especially true for women with carcinosarcomas showing a 5 -year overall survival rate of only $30 \%$. Since a small group of patients did not receive radiotherapy in this series, a comparison was made of the outcome for this subgroup and for patients treated according to the standard protocol for this time period. No significant differences were found between these groups with regard to tumor control, recurrences or survival. Even after correction for differences with regard to tumor stage, histology, and number of mitoses (Cox multivariate analyses) no differences appeared. Local and regional tumor control and recurrences were also similar for these groups. For high-risk endometrial carcinomas it has been shown that the addition of chemotherapy to postoperative pelvic radiotherapy significantly increased the survival rate in a randomized multicenter study. Since carcinosarcomas are thought to belong to endometrial carcinomas and constitute a new high-risk group within this diagnosis, a combination of radiotherapy and chemotherapy is probably the treatment choice for this group until further studies are available (39). Leiomyosarcomas and endometrial stromal cell sarcomas are separate entities and they should probably be treated according to other, and diagnosis specific, protocols. Radiotherapy increased early and late tissue reactions and side effects but was overall rather well tolerated. In this series as in others, $5-10 \%$ serious late radiation reactions from bladder and intestine were expected to occur.

Further studies are needed to define the role of radiotherapy, but also chemotherapy, and a combination of both. More attention must also be paid to vaginal brachytherapy and in some cases external beam therapy may be omitted or perhaps replaced by chemotherapy. Hormonal therapy $(40,41)$ and targeted drug therapy $(42,42)$ should be further evaluated in forthcoming trials. The different types of uterine sarcomas should be studied separately and carcinosarcomas studied together with high-risk endometrial carcinomas.

\section{References}

1. Tavassoli FA and Devilee P (eds): Pathology and genetics: Tumours of the breast and female genital organs. WHO classification of tumours series, IARC Press, Lyon, 2003.

2. Disaia PJ and Creasman WT: Sarcoma of the uterus. In: Clinical Gynecologic Oncology. Disaia PJ and Creasman WT (eds). Mosby, St. Louis, pp173-184, 2002.

3. Harlow BL, Weiss NS and Lofton S: The epidemiology of sarcomas of the uterus. J Natl Cancer Inst 76: 399-402, 1986.

4. Pautier P, Genestie C, Rey A et al: Analysis of clinico-pathologic prognostic factors for 157 uterine sarcomas and evaluation of a grading score validated for soft tissue sarcoma. Cancer 88 : 1425-1431, 2000

5. Livi L, Paiar F, Shah N, Blake P, Villanucci A, Amunni G, Barca R, Judson I, Lodge N, Meldolesi E, Simontacchi G, Piperno G, Galardi A, Scoccianti S, Biti GP and Harmer C: Uterine sarcoma: Twenty-seven years of experience. Int J Radiat Oncol Biol Phys 57: 1366-1373, 2003.
6. Rose PG, Piver MS, Tsukada Y and Lau T: Patterns of metastasis in uterine sarcoma. An autopsy study. Cancer 63: 935-938, 1989.

7. Sagae S, Yamashita K, Ishioka S, Nishioka Y, Terasawa K, Mori M, Yamashiro K, Kanemoto T and Kudo R: Preoperative diagnosis and treatment results in 106 patients with uterine sarcoma in Hokkaido, Japan. Oncology 67: 33-9, 2004.

8. Gadducci A, Landoni F, Sartori E, Zola P, Maggino T, Lissoni A, Bazzurini L, Arisio R, Romagnolo C and Cristofani R: Uterine leiomyosarcomas: Analysis of Treatment Failures and Survival. Gynecol Oncol 62: 25-32, 1996.

9. Major FJ, Blessing JA, Silverberg SG, Morrow CP, Creasman WT, Currei JL, et al: Prognostic factors in early stage uterine sarcoma. A Gynecologic Oncology Group study. Cancer 71: 1702-1709, 1993

10. Chi DS, Mychalczak B, Saigo PE, Recigno J and Brown CL: The role of whole-pelvic irradiation in the treatment of earlystage uterine carcinosarcoma. Gynecol Oncol 65: 493-498, 1997.

11. Benoit L, Arnould L, Cheynel N, Goui S, Collin F, Fraisse J and Cuisenier $\mathrm{J}$ : The role of surgery and treatment trends in uterine sarcoma. Eur J Surg Oncol 31: 434-442, 2005.

12. Peters WA, Fleming WP and Morley GW: Prognostic features of sarcomas and mixed tumors of the endometrium. Obstet Gynecol 63: 550-556, 1984.

13. Arrastia CD, Fruchter RG, Clark M, et al: Uterine carcinosarcomas: Incidence and trends in management and survival. Gynecol Oncol 65: 158-63, 1997.

14. Silverberg SG, Major FJ, Blessing JA, Fetter B, Askin FB, Liao S-Y and Miller A: Carcinosarcoma (malignant mixed mesodermal tumor) of the uterus: A Gynecologic Oncology Group pathologic study of 203 cases. Int J Gynecol Pathol 9: $1-9,1990$.

15. Villena-Heinsen C, Diesing C, Fischer D, Griesinger D, Maas G, Diedrich N and Friedrich M: Carcinosarcomas - a retrospective analysis of 21 patients. Anticancer Res 26: 4817-4823, 2006.

16. Pautier P, Rey A, Haie-Meder C, Kerbrat P, Dutel JL, Gesta P, Bryard F, Morice P, Duvillard P and Lhomme C: Adjuvant chemotherapy with cisplatin, ifosfamide, and doxorubicin followed by radiotherapy in localized uterine sarcomas: results of a case-control study with radiotherapy alone. Int J Gynecol Cancer 14: 1112-1117, 2004

17. Odunsi K, Moneke V, Tammela J, Ghamande S, Seago P, Driscoll D, Marchetti D, Baker T and Lele S: Efficacy of adjuvant CYVADIC chemotherapy in early-stage uterine sarcomas: results of long-term follow-up. Int J Gynecol Cancer 14: 659-664, 2004.

18. Nordal RR, Kristensen GB, Stenwig AE, Nesland JM, Pettersen EO and Tropé CG: An evaluation of prognostic factors in uterine carcinosarcoma. Gynecol Oncol 67: 316-321, 1997.

19. Bodner K, Bodner-Adler B, Kimberger O, Czerwenka K, Leodolter $\mathrm{S}$ and Mayerhofer K: Evaluating prognostic parameters in women with uterine leiomyosarcomas. A clinicopathologic study. J Reprod Med 48: 95-100, 2003.

20. Morice P, Rodrigues A, Pautier P, Rey A, Camatte S, Atallah D, Pomel C, Lhomme C, Haie-Meder C, Duvillard P and Castaigne D: Surgery for uterine sarcoma: review of the literature and recommendations for the standard surgical procedure. Gyn Obstet Fert 31: 147-150, 2003.

21. Dinh TA, Oliva EA, Fuller AF Jr, Lee H and Goodman A: The treatment of uterine leiomyosarcoma. Results from a 10-year experience (1990-1999) at the Massachusetts General Hospital. Gynecol Oncol 92: 648-652, 2004.

22. Gard GB, Mulvany NJ and Quinn MA: Management of uterine leiomyosarcoma in Australia. Aust NZ J Obstet Gynaecol 39: 93-98, 1999.

23. Kelly KL and Craighead PS: Characteristics and management of uterine sarcoma patients treated at the Tom Baker Cancer Centre. Int J Gynecol Cancer 15: 132-139, 2005.

24. Brooks SE, Zhan M, Cote T and Baquet CR: Surveillance, epidemiology, and end results analysis of 2677 cases of uterine sarcoma 1989-1999. Gynecol Oncol 93: 204-208, 2004.

25. Soumarova R, Horova H, Seneklova Z, Ruzickova J, Horova I, Budikova M, Slampa P and Kalabova R: Treatment of uterine sarcoma. A survey of 49 patients. Archiv Gynecol Obstet 266: 92-95, 2002.

26. Riddle PJ, Echeta CB, Manek S, Lavery BA, Charnock FM, Mackenzie I and Ganesan TS: Retrospective study of management of uterine sarcomas at Oxford 1990-1998: role of adjuvant treatment. Clin Oncol 14: 54-61, 2002. 
27. Le T: Adjuvant pelvic radiotherapy for uterine carcinosarcomas in a high risk population. Eur J Surg Oncol 27: 282-285, 2001.

28. Ferrer F, Sabater S, Farrus B, Guedea F, Rovirosa F, Anglada L, Delannes M, Marin S, DuBois JB and Daly-Schveitzer N: Impact of radiotherapy on local control and survival in uterine sarcomas: a retrospective study from the Group Oncologic Catala-Occita. Int J Radiat Oncol Biol Phys 44: 47-52, 1999.

29. Knocke TH, Kucera H, Dorfler D, Pokrajac B and Potter R: Results of postoperative radiotherapy in the treatment of sarcoma of the corpus uteri. Cancer 83: 1972-1979, 1998.

30. Etiz D, Garipaaolu M, Etiz EE, Kose FM, Kayikciolu F, Haberal A, Citak L and Cakmak A: Results of postoperative radiotherapy in the treatment of 29 uterine sarcoma patients. Tumori 89: 183-188, 2003.

31. Chi DS, Mychalczak B, Saigo PE, Rescigno J and Brown CL: The role of whole-pelvic irradiation in the treatment of earlystage uterine carcinosarcomas. Gynecol Oncol 65: 493-498, 1997.

32. Numa F, Umayahara K, Ogata H, Nawata S, Sakaguchi Y, Emoto T, Kawasaki K, Hirakawa H, Sase M, Oga A and Kato H: De novo uterine sarcoma with good response to neo-adjuvant chemotherapy. Int J Gynecol Cancer 13: 364-367, 2003.

33. Kushner DM, Webster KD, Belinson JL, Rybicki LA, Kennedy AW and Markman M: Safety and efficacy of adjuvant single-agent ifosfamide in uterine sarcoma. Gynecol Oncol 78: 221-227, 2000.

34. Toyoshima M, Akahira J, Matsunaga G, Niikura H, Ito K, Yaegashi $\mathrm{N}$ and Tase $\mathrm{T}$ : Clinical experience with combination paclitaxel and carboplatin therapy for advanced or recurrent carcinosarcomas of the uterus. Gynecol Oncol 94: 774-778, 2004.

35. Wu TI, Chang TC, Hsueh S, Hsu KH, Chou HH, Huang HJ and Lai $\mathrm{CH}$ : Prognostic factors and impact of adjuvant chemotherapy for uterine leiomyosarcoma. Gynecol Oncol 100: $166-172,2006$
36. Soh LT, Chew SH and Ang L: Uterine leiomyosarcoma - a Singapore experience. Aust NZ J Obstet Gynaecol 39: 246-248, 1999.

37. Menczer J, Levy T, Piura B, Chetrit A, Altaras M, Meirovitz M, Glezerman M, Fishman A: A comparison between different postoperative modalities of uterine carcinosarcomas. Gynecol Oncol 97: 166-170, 2005.

38. Kanjeekal S, Chambers A, Fung FMK and Verma S: Systematic therapy for advanced uterine sarcoma: a systematic review of the literature. Gynecol Oncol 97: 624-637, 2005.

39. McCluggage WG: Uterine carcinosarcomas (malignant mixed Mullerian tumors) are metaplastic carcinomas. Int J Gynecol Cancer 12: 687-690, 2002.

40. Diesing D, Cordes T, Finas D, Loning M, Mayer K, Diedrich K and Friedrich M: Endometrial stromal sarcomas - a retrospective analysis of 11 patients. Anticancer Res 26: 655-661, 2006.

41. Bodner K, Bodner-Adler B, Kimberger O, Czerwenka K, Leodolter $\mathrm{S}$ and Mayerhofer K: Estrogen and progesterone receptor expression in patients with uterine leiomyosarcoma and correlation with different clinicopathological parameters. Anticancer Res 23: 729-732, 2003.

42. Livasy CA, Reading FC, Moore DT, Boggess JF and Lininger RA EGFR expression and HER2/neu overexpression/amplification in endometrial carcinosarcomas. Gynecol Oncol 100: 101-106, 2006.

43. Raspollini MR, Susini T, Amunni G, Paglierani M, Castiglione F, Garbini F, Carriero C, Scarselli G and Taddei GL: Expression and amplification of HER-2/neu oncogene in uterine carcinosarcomas: a marker for potential molecularly targeted treatment? Int J Gynecol Cancer 16: 416-422, 2006. 